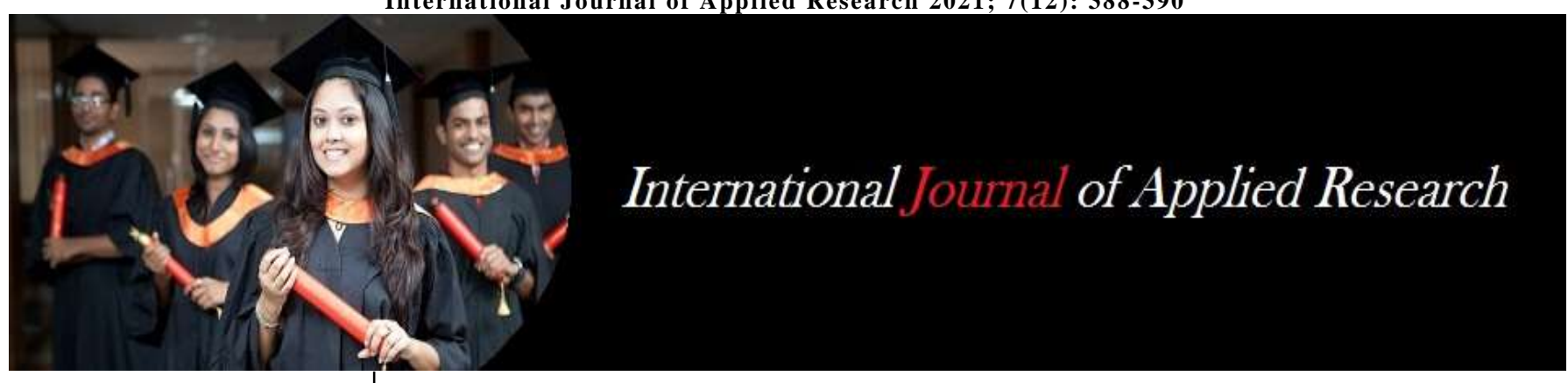

ISSN Print: 2394-7500 ISSN Online: 2394-5869 Impact Factor: 8.4

IJAR 2021; 7(12): 388-390 www.allresearchjournal.com Received: 04-10-2021 Accepted: 15-11-2021

पूजा पोखरिया

शोध छात्र, गृह विज्ञान विभाग, डी० एस० बी० कैम्पस, कुमाऊँ विश्वविद्यालय, नैनीताल, उत्तराखण्ड, भारत
Corresponding Author: पूजा पोखरिया शोध छात्र, गृह विज्ञान विभाग, डी० एस० बी० कैम्पस, कुमाऊँ विश्वविद्यालय, नैनीताल, उत्तराखण्ड, भारत

\section{पर्वतीय क्षेत्र की गर्भवती महिलाओं की स्वास्थ्य स्थिति का अध्ययन (नैनीताल जिले के सन्दर्भ में)}

\section{पूजा पोखरिया}

DOI: https://doi.org/10.22271/allresearch.2021.v7.i12f.9275

सारांश

मातृत्व शब्द में ही सम्पूर्ण सृष्टि समाई है। मातृत्व एक प्राकृतिक सत्य है। भारत सभ्यता के विकास के पूर्व भी सृष्टि के अस्तित्व एवं निरन्तरता के लिए सर्वाधिक महत्वपूर्ण एवं अनिवार्य कारक मातृत्व ही था। स्वास्थ्य के संदर्भ में सबसे महत्वपूर्ण समस्या गर्भवती महिलाओं के स्वास्थ्य से सम्बन्धित है क्योंकि एक स्वस्थ माँ ही एक स्वस्थ शिशु को जन्म दे सकती है और स्वस्थ शिशु ही राष्ट्र का आधार होते हैं। प्रस्तुत शोध उत्तराखण्ड राज्य के नैनीताल जिले में किया गया है। नैनीताल जिले में 8 विकासखण्ड हैं। इन विकासखण्डों में से शोध हेतु 4 विकासखण्डा भीमताल, रामगढ़, बेतालघाट, धारी विकासखण्डों का चयन किया गया है। शोध कार्य में यादृच्छिक विधि (Random Sample) द्वारा किया है। कुल 200 ग्रामीण गर्भवती महिलाओं का चयन किया गया है। शोध कार्य में 18-45 वर्ष आयु की ग्रामीण गर्भवती महिलाओं की स्वास्थ्य सम्बन्धित स्थिति का अध्ययन करने के लिए प्रश्नावली का निर्माण किया गया है। अध्ययन में पाया गया कि पर्वतीय क्षेत्र की ग्रामीण गर्भवती महिलायें अपने होने वाले बच्चे एवं अपने स्वास्थ्य के प्रति सचेत थी। ग्रामीण गर्भवती महिलायें स्वास्थ्य केन्द्र मे समय समय पर डॉक्टरी परीक्षण करवाती थी और सामुदायिक स्वास्थ्य केन्द्र से मिलने वाली सुविधाओं का लाभ ले रही थी परन्तु पर्वतीय क्षेत्रो में सामुदायिक स्वास्थ्य केन्द्रों में संसाधनों व सुविधाओं का अभाव है।

कूट शब्द: मातृत्व एक प्राकृतिक सत्य, गर्भवती महिलाओं की स्वास्थ्य स्थिति, नैनीताल

\section{प्रस्तावना:}

स्वास्थ्य जीवन की सफलता की कुंजी है। जीवन में सफल होने के लिए सबसे पहले मनुष्य के शरीर का स्वस्थ होना आवश्यक है। यही बात राष्ट्र के लिए भी लाग होती है। देश के नागरिक जितने अधिक स्वस्थ होंगे, देश विकास सूचकांक की कसौटियों पर उतना ही अच्छा प्रदर्शन करेगा। एक विदेशी विद्वान डॉ० बेनेडिक्ट जस्ट ने कहा है- "उत्तम स्वास्थ्य वह अनमोल रत्न है, जिसका मूल्य तब ज्ञात होता है, जब वह खो जाता है।" विश्व स्वास्थ्य संगठन की परिभाषा के अनुसार-“स्वास्थ्य पूर्णतः शारीरिक मानसिक एवं सामाजिक तन्दुरुस्ती की स्थिति है, केवल रोग या अपंगता का अभाव नहीं“। ग्रामीण महिलाएँ- ग्रामीण महिलाओं से अभिप्राय उन महिलाओं से है जो ग्रामीण क्षेत्रों में निवास करती हैं जिनका मुख्य कार्य कृषि, पशुपालन के साथ घरेलू कार्य करना है। गर्भावस्था में स्वास्थ्य का महत्वपूर्ण योगदान होता है क्योंकि स्वस्थ शिशु को जन्म देने के लिए माता का स्वस्थ रहना अति आवश्यक है। कहा जाता है- "एक स्वस्थ माँ ही स्वस्थ शिशु को जन्म देने में सक्षम हो सकती है।" गर्भावस्था में स्त्री के शरीर में एक नये जीव का निर्माण होता है और कई प्रकार के उपापचयन सम्बन्धी परिवर्तन भी होते हैं। भ्रूण की उचित विकास हेतु सही से प्रसव हेतु तथा जन्म के बाद भी कोई परेशानियाँ ना हो उसके लिये गर्भवती महिलाओं का स्वस्थ रहना आवश्यक है। गर्भावस्था में महिलाओं का आहार एवं स्वास्थ्य की देख-रेख की विशेष आवश्यकता होती है। शिशु के जन्म तक माँ और शिशु का स्वास्थ्य एक दूसरे से जुड़ा होता है। अतः समय-समय पर भ्रूण के विकास को जाँचा जाता है और माँ के स्वास्थ्य को भी देखा जाता है। स्वस्थ माँ बनने तथा स्वस्थ शिशु को जन्म देने के लिए किशोरावस्थ से ही बालिका के भोजन पर ध्यान देने चाहिए।

\section{उद्देश्य}

1. चयनित गर्भवती महिलाओं की स्वास्थ्य स्थिति का अध्ययन करना।

2. चयनित गर्भवती महिलाओं को स्वास्थ्य के प्रति जागरूक करना। 


\section{शोध विधि}

1. प्रस्तुत शोध उत्तराखण्ड राज्य के नैनीताल जिले में किया गया है। नैनीताल जिले से 4 विकाखण्डों चयन किया गया हैं। शोध कार्य हेतु भीमताल, रामगढ़, बेतालघाट, धारी विकासखण्डों का चयन किया गया है।

2. शोध कार्य यादृच्छिक विधि (Random Sample) द्वारा किया गया है।

3. शोध कार्य हेतु चयनित विकासखण्डों में से कुल 200 ग्रामीण गर्भवती महिलाओं का चयन किया गया है।

4. न्यायदर्श में सम्मिलित ग्रामीण गर्भवती महिलाओं के चयन हेतु मुख्य चिकित्सा अधिकार (C.M.O.) नैनीताल की सहायता से नर्स मिडवाइफरी (A.N.M.) के दूरभाष नम्बर लिये गये। तदोपरान्त यादृच्छिक विधि द्वारा प्रत्येक विकासखण्ड से 50-50 ग्रामीण गर्भवती महिलाओं का चयन किया गया है।

5. शोध कार्य हेतु $18-45$ वर्ष आयु की ग्रामीण गर्भवती महिलाओं का चयन किया गया है। स्वास्थ्य सम्बन्धित जानकारी, का अध्ययन करने के लिए प्रश्नावली का निर्माण किया गया है। अवलोकन तथा साक्षात्कार के माध्यम से चयनित ग्रामीण गर्भवती महिलाओं से जानकारी प्राप्त की गई।

\section{साहित्य समीक्षा:}

सन्तोष पटेल एट ऑल (2021) ने अपने अध्ययन में भोपाल मध्य प्रदेश की प्रसूति एवं स्त्री रोग विभाग, सामुदायिक चिकित्सा विभाग में भर्ती 123 गर्भवती महिलाओं में अध्ययन किया जो 18-45 वर्ष आयु की थीं। अध्ययन से ज्ञात होता है कि 67.4 प्रतिशत महिलाओं की आयु 18 से 19 वर्ष थी और 91.8 गर्भवती महिलायें गृहिणी थीं तथा 34.1 प्रतिशत महिलाओं के पति कारखाने के मजदूर थे एवं 75.6 प्रतिशत गर्भवती संयुक्त परिवार में निवास कर रही थीं। महिलाओं की सामाजिक-आर्थिक स्थिति निम्न आय वर्ग से सम्बन्धित थी।

ग्लोबल न्यूटीशन रिपोर्ट (2017) के आँकड़ों के अनुसार - प्रजनन क्षमता वाली आयु की 51 प्रतिशत महिलाएँ अभी भी एनिमिक हैं, जो चिंताजनक आँकड़ें समाज की सोच और सिस्टम दोनों को जिम्मेदार मानते हैं, देश में आज भी गर्भवती महिला की सेहत और खानपान को पति और परिवार गम्भीरता से नहीं लेते है। वैश्विक पोषण रिपोर्ट (2017) के अनुसार - दुनिया भर में 51 प्रतिशत महिलाएँ एनीमिक हैं। केन्द्रीय वित्त मंत्री अरुण जेटली ने भी संसद में आर्थिक सर्वेक्षण 18 पेश करते वक्त कहा कि भारत के लिए बाल व मातृ कुपोषण आज भी एक बड़ी चुनौती है। मोरीसन इट ऑल (2012) ने अपने अध्ययन 210 गर्भवती महिलाओं का चयन किया, जिसमें उन्होंने सामाजिक-आर्थिक स्थिति एवं गर्भावस्था के समय में विशेष तनाव को लेकर प्रश्नावली का निर्माण किया। निष्कर्ष निकाला कि परिवार की आय, पति का व्यवसाय, शिक्षा यह तीन बातें गर्भावस्था के समय में तनाव उत्पन्न करती हैं और उन्होंने अपने अध्ययन देखा कि 27 से 32 वर्ष आयु की गर्भवती महिलाओं में तनाव की स्थिति अधिक पाई जाती है।

हरलाक के अनुसार संतानोत्पत्ति के लिये स्त्री की आयु कम से कम 21 वर्ष होनी चाहिये क्योंकि इस आयु में परिपक्वता आ जाती है जिससे उत्पन्न शिशु शारीरिक रूप से स्वस्थ होते हैं।

\section{परिणाम एवं व्याख्या \\ गर्भवती महिलाओं की सामाजिक-आर्थिक स्थिति तालिका संख्या 1-7 में प्रस्तुत की गयी है। \\ प्रस्तुत शोध पत्र में पर्वतीय क्षेत्र की ग्रामीण गर्भवती महिलाओं की उम्र, स्वास्थ्य केन्द्र में पंजीकरण, पंजीकरण के बाद जाँच,}

टिटनेस टॉक्साइड के टीके, डॉक्टरी परीक्षण, व्यायाम, गर्भावस्था के दौरान तनाव की स्थिति सम्बन्धित स्थिति का वर्णन किया गया है।

तालिका 1: उम्र के आधार पर उत्तरदाताओं का वर्गीकरण

\begin{tabular}{|c|c|c|c|}
\hline $\begin{array}{c}\text { क्र0 } \\
\text { सं0 }\end{array}$ & $\begin{array}{c}\text { उत्तरदाताओं की उम्र } \\
\text { (वर्ष में) }\end{array}$ & $\begin{array}{c}\text { उत्तरदाताओं की } \\
\text { संख्या }\end{array}$ & प्रतिशत \\
\hline 1 & $18-24$ & 83 & 41.5 \\
\hline 2 & $25-30$ & 85 & 42.5 \\
\hline 3 & $35-40$ & 28 & 14.0 \\
\hline 4 & 40 & 4 & 2 \\
\hline \multicolumn{2}{|c|}{ योग } & 200 & 100 \\
\hline
\end{tabular}

शोध में यह देखा गया कि 41.5 प्रतिशत ग्रामीण गर्भवती महिलाओं की आयु 18-24 वर्ष थी, 42.5 प्रतिशत गर्भवती महिलाओं की आयु 25-30 वर्ष की थी, 14 प्रतिशत गर्भवती महिलाओं की आयु 35-40 वर्ष थी, केवल 2 प्रतिशत गर्भवती महिलाओं की आयु 40 वर्ष थी। अध्ययन के आधार पर यह ज्ञात होता है कि ग्रामीण क्षेत्रों में विवाह प्राय: कम उम्र में होने के कारण महिलायें कम उम्र में ही गर्भवती हो जाती है तथा कम उम्र में गर्भवती होने से उनके स्वास्थ्य पर दुष्प्रभाव पड़ता है जिसमें पौष्टिक भोजन का अभाव परिलक्षित होता है क्योंकि सम्पन्नता होने के बावजूद सही जानकारी नहीं होती है।

तालिका 2: गर्भावस्था के दौरान स्वास्थ्य केन्द्र में पंजीकरण के आधार पर वर्गीकरण

\begin{tabular}{|c|c|c|c|}
\hline $\begin{array}{c}\text { क्र0 } \\
\text { सं0 }\end{array}$ & $\begin{array}{c}\text { स्वास्थ्य केन्द्र में } \\
\text { पंजीकरण }\end{array}$ & $\begin{array}{c}\text { उत्तरदाताओं की } \\
\text { संख्या }\end{array}$ & प्रतिशत \\
\hline 1 & हाँ & 194 & 97 \\
\hline 2 & अभी नहीं & 6 & 3 \\
\hline & योग & 200 & 100 \\
\hline
\end{tabular}

शोध में यह देखा गया कि 97 प्रतिशत गर्भवती महिलाओं ने गर्भावस्था के दौरान स्वास्थ्य केन्द्र में पंजीकरण कराया था जबकि 3 प्रतिशत गर्भवती महिलाओं ने गर्भावस्था के दौरान स्वास्थ्य केन्द्र में पंजीकरण नहीं करवाया था। क्योंकि कुछ गर्भवती महिलाओं का गर्भावस्था के समय दुसरा महीना चल रहा था और कुछ गर्भवती महिलाओं का कहना था कि चार से पांच महीने में स्वस्थ्य केन्द्र में दिखाना चाहिए। पूनम गोयल (2019) ने अपने अध्ययन में देखा कि 92.33 प्रतिशत ग्रामीण गर्भवती महिलाओं ने गर्भावस्था के दौरान स्वास्थ्य केन्द्र में पंजीकरण करवाया था। 7.66 प्रतिशत महिलाओं ने स्वास्थ्य केन्द्र में पंजीकरण नहीं करवाया था।

तालिका 3: स्वास्थ्य केन्द्र में पंजीकरण के बाद जाँच के आधार पर वर्गीकरण

\begin{tabular}{|c|c|c|c|}
\hline क्र0सं0 & स्वास्थ्य केन्द्र में पंजीकरण & उत्तरदाताओं की संख्या & प्रतिशत \\
\hline 1 & हाँ & 183 & 91.5 \\
\hline 2 & नहीं & 8 & 4 \\
\hline 3 & अभी नहीं & 9 & 4.5 \\
\hline & योग & 200 & 100 \\
\hline
\end{tabular}

शोध में यह देखा गया कि 91.5 प्रतिशत गर्भवती महिलाओं ने स्वास्थ्य केन्द्र में पंजीकरण के बाद जांच करवाई थी, 4 प्रतिशत महिलाओं ने स्वास्थ्य केन्द्र में पंजीकरण के बाद जांच नहीं करवाई थी, 4.5 प्रतिशत गर्भवती महिलाओं के तीन महीने पूर्ण ना होने के कारण उन्होंने जांच नहीं करवाई थी। 
तालिका 4: टिटनेस टॉक्साइड के टीके के आधार पर वर्गीकरण

\begin{tabular}{|c|c|c|c|}
\hline क्र0सं0 & टिटनेस टॉक्साइड के टीके & उत्तरदाताओं की संख्या & प्रतिशत \\
\hline 1 & हाँ & 192 & 96 \\
\hline 2 & नहीं & 1 & 0.5 \\
\hline 3 & अभी नहीं & 7 & 3.5 \\
\hline & योग & 200 & 100 \\
\hline
\end{tabular}

शोध में यह देखा गया कि 96 प्रतिशत गर्भवती महिलाओं ने टिटनेस-टॉक्साइड के टीके लगवाए थे, 0.5 प्रतिशत गर्भवती महिलाओं ने टिटनेस ऑक्साइड के टीके नहीं लगवाये थे, 3.5 प्रतिशत गर्भवती महिलाओं ने गर्भावस्था के समय तीन महीने ना होने के कारण टिटनेस टॉक्साइड के टीके नहीं लगवाये थे। किरन बाला (2017) ने अपने अध्ययन में देखा कि 56.30 प्रतिशत ग्रामीण महिलाओं का मानना था कि गर्भावस्था में टीके लगवाने चाहिए जबकि 43.70 प्रतिशत ग्रामीण महिलाओं का मानना था कि गर्भावस्था में टीके नहीं लगवाने चाहिए।

तालिका 5: गर्भावस्था में डॉक्टरी परीक्षण करवाने के आधार पर वर्गीकरण

\begin{tabular}{|c|c|c|c|}
\hline क्र0सं० & गर्भावस्था में डॉक्टरी परीक्षण करवाती हैं? & कुल योग & प्रतिशत \\
\hline 1 & हाँ & 192 & 96 \\
\hline 2 & नहीं & 8 & 4 \\
\hline & योग & 200 & 100 \\
\hline
\end{tabular}

शोध में यह देखा गया कि 96 प्रतिशत गर्भवती महिलाओं ने गर्भावस्था के समय डॉक्टरी परीक्षण करवाया था, 4 प्रतिशत गर्भवती महिलाओं ने गर्भावस्था के समय डॉक्टरी परीक्षण नहीं करवाया था। कविता (2005) ने अपने अध्ययन में बताया कि 53. 33 प्रतिशत गर्भवती महिलाओं ने डॉक्टरी परीक्षण करवाया था, जबकि 46.67 प्रतिशत महिलाओं ने डॉक्टरी परीक्षण नहीं कराया था

तालिका 6: गर्भवती महिलाओं द्वारा व्यायाम के आधार पर वर्गीकरण

\begin{tabular}{|c|c|c|c|}
\hline क्र0सं0 & व्यायाम & उत्तरदाताओं की संख्या & प्रतिशत \\
\hline 1 & हाँ & 14 & 7.0 \\
\hline 2 & नहीं & 186 & 93.0 \\
\hline & योग & 200 & 100 \\
\hline
\end{tabular}

शोध में यह देखा गया कि 7 प्रतिशत गर्भवती महिलायें व्यायाम करती थी। 93 प्रतिशत गर्भवती महिलायें व्यायाम नहीं करती थी। अधिकांश गर्भवती महिलायें व्यायाम नहीं करती हैं क्योंकि पर्वतीय क्षेत्र की ग्रामीण गर्भवती महिलाओं के पास समय का अभाव था।

तालिका 7: गर्भावस्था के दौरान तनाव के आधार पर वर्गीकरण

\begin{tabular}{|c|c|c|c|}
\hline क्र0सं0 & गर्भावस्था के दौरान तनाव & उत्तरदाताओं की संख्या & प्रतिशत \\
\hline 1 & हाँ & 13 & 6.5 \\
\hline 2 & नहीं & 187 & 93.5 \\
\hline & योग & 200 & 100 \\
\hline
\end{tabular}

शोध में यह देखा गया कि 6.5 प्रतिशत गर्भवती महिलाओं को गर्भावस्था के समय तनाव की रिथति थी, 93.5 प्रतिशत गर्भवती महिलाओं को गर्भावस्था के समय किसी भी प्रकार का तनाव नहीं था, कुछ गर्भवती महिलाओं का कहना था कि हमारी आर्थिक स्थिति ठीक नहीं है और लड़के की चाह में अधिक बच्चों को जन्म दिया था।

\section{निष्कर्ष}

पर्वतीय क्षेत्र की ग्रामीण गर्भवती महिलाओं की स्वास्थ्य स्थिति के सम्बन्ध में अध्ययन से यह ज्ञात होता है कि पर्वतीय क्षेत्र की ग्रामीण गर्भवती महिलायें अपने होने वाले बच्चे एवं अपने स्वास्थ्य के प्रति जागरूक तो है परन्तु पर्वतीय क्षेत्रो में स्वास्थ्य सुविधाओं का अभाव है। कहीं सामुदायिक स्वास्थ्य केन्द्र डॉक्टर है तो कहीं मशीनों व संसाधनों का अभाव है। जिस कारण ग्रामीण गर्भवती महिलाओं को विशेष रूप से स्वास्थ्य सम्बन्धी समस्याओं का सामना करना पड़ता है। पर्वतीय क्षेत्र में हर साल अनेक गर्भवती महिलाओं को उचित स्वास्थ्य सुविधाएँ न मिलने के कारण प्रसव के समय परेशानियाँ होती हैं। आज जब हर तरफ विकास के भूमण्डलीय नारे लगाये जा रहे हैं वहीं दूसरी ओर पर्वतीय क्षेत्र की ग्रामीण गर्भवती महिलाओं का जीवन इतना कष्टमय है कि उसे शब्दों में बयाँ नहीं किया जा सकता है। यहाँ ग्रामीण महिलाएँ परिवार की जिम्मेदारियों के बोझ से इस प्रकार दबी हुयी हैं कि उन्हें अपने लिये समय ही नहीं मिल पाता है। अतः ग्रामीण गर्भवती महिलाओं को स्वास्थ्य सुविधा, उन्हें समय पर पोषाहार, स्वच्छता आदि के विविध आयामों से अवगत कराने की भी आवश्यकता है। अतः समाज में परिवर्तन लाने के लिये पर्वतीय क्षेत्र की गर्भवती महिलाओं के स्वास्थ्य का विशेष ध्यान देना होगा। महिला सशक्तिकरण राज्य सरकार की प्राथमिकता है। एक महिला स्वस्थ होगी तो समाज, राज्य व देश भी स्वस्थ होगा। अतः आज ग्रामीण गर्भवती महिलाओं को लेकर समाज व सरकार को और अधिक जागरूक होना होगा। ऐसा करके ही सर्वश्रेष्ठ भारत की कल्पना की जा सकती है।

\section{सन्दर्भ सूची}

1. पुष्पांजलि (2018) भारतीय महिलाओं की स्वास्थ्य स्थिति और मैथोडिस्ट गर्ल्स पी० जी० कॉलेज रुड़की, हरिद्वार Indian J. Soc. and pol. 05 (1) :2018: 115-16 Special Issue UGC पृष्ठ संख्या 116।

2. नेहरा कुमार डॉ० राकेश (2017) प्राथमिक स्वास्थ्य केन्द्र व ग्रामीण स्वास्थ्य राजस्थान के सन्दर्भ में खण्ड स्तरीय अध्ययन International Journal of Applied Research

3. कविता (2005) "काशी की कुछ ग्रामीण एवं शहरी गर्भवती महिलाओं के आहारीय पोषण का तुलनात्मक अध्ययन" श्री अग्रसेन कन्या स्वायत्तशासी पी०जी० कॉलेज वाराणसी, पृष्ठ सं०-2।

4. किरन बाला (2017) ग्रामीण महिलाओं की स्वास्थ्य समस्याएँ एवं समाधान : एक समाजशास्त्रीय अध्ययन, कुमाऊँ विश्वविद्यालय नैनीताल पृष्ठ सं०-6।

5. Patel Santosh, Suxit Jain, Chitti Babu G, Masuram Bharath Kumar. International Journal of Community Medicine and Public Health 2021;8(1): 402-406.

6. Morrison J, Najman JM, Williams GM, Keeping JD, Andersen MJ. "Socio-Economic Status and Pregnancy outcome" An Australian Study Br. J Obstet Gyanacol 1989;96(3):298-307.

7. पूनम गोयल 2019 राष्टीय ग्रामीण स्वास्थ्य मिशन के अन्तर्गत ग्रामीण गर्भवती महिलाओं एवं नवजात शिशुओं को प्राप्त सेवओं का विश्लेषणात्मक अध्ययन शासकीय कमलाराज कन्या स्नाकोत्तर स्वशासी महाविघालय ग्वालियर (म० प०) पृष्ठ संख्या 178।

8. खनूजा रानी (2011) आहार एवं पोषण विज्ञान अग्रवाल पब्लिकेशन, अगरा-2 पृष्ठ सं०- 412 ।

9. https://wwwgaunconnection.com 